CASTRO, W.J.R. et al. Suplementação de bovinos na seca. PUBVET, Londrina, V. 8, N. 5, Ed. 254, Art. 1685, Março, 2014.

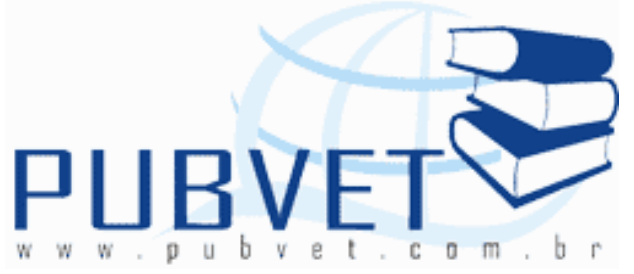

PUBVET, Publicações em Medicina Veterinária e Zootecnia.

\title{
Suplementação de bovinos na seca
}

Wanderson José Rodrigues de Castro ${ }^{1}$, Michele Carolina Rodrigues de Castro ${ }^{2}$, Geferson Antonio Fernandes ${ }^{3}$, Fabíola Francisca Dias Fernandes ${ }^{4}$, Vitor Tavares Oliveira Borges ${ }^{1}$, Claudio Jonasson Mousquer ${ }^{1}$, Tiago Adriano Simioni $^{5}$, Fagton de Mattos Negrão ${ }^{6}$

1 Mestrando em Ciência Animal da Universidade Federal de Mato Grosso, Campus Cuiabá-MT

${ }^{2}$ Bióloga, Universidade Federal de Mato Grosso, campus de Rondonópolis-MT

${ }^{3}$ Zootecnista - Universidade Federal de Mato Grosso, Sinop-MT

${ }^{4}$ Medica Veterinária - Universidade Federal de Mato Grosso, Sinop-MT

${ }^{5}$ Mestrando em Zootecnia da Universidade Federal de Mato Grosso, Campus Sinop-MT

${ }^{6}$ Doutorando em Ciência Animal da Universidade Federal de Mato Grosso, Cuiabá-MT

\section{Resumo}

O maior problema no período da seca é o baixo desempenho dos bovinos em pastejo, resultado de uma pastagem de baixo valor nutricional. A suplementação de bovinos no período crítico do ano é de suma importância para a pecuária brasileira, de modo que venha minimizar os prejuízos causados pela mesma, porém o fato dos produtores não se prepararem para o que já é previsto, causa grande transtorno dentro das propriedades, sendo 
CASTRO, W.J.R. et al. Suplementação de bovinos na seca. PUBVET, Londrina, V. 8, N. 5, Ed. 254, Art. 1685, Março, 2014.

assim o uso da técnica de suplementação seja ela via concentrado ou volumoso traz grandes benefícios para este período que é considerado o mais crítico dentro da pecuária.

Palavras-chave: Capineiras; Diferimento; Inverno

\title{
Supplementation of Cattle in drought
}

\begin{abstract}
The biggest problem in the dry season is the low performance of grazing cattle, the result of a pasture of low nutritional value. Supplementation of cattle in the critical period of the year is of paramount importance for Brazilian cattle, so that will minimize the damage caused by it, but the fact that the producers did not prepare for what is already planned, causes great disorder within the properties, so the use of the technique of supplementation either via concentrated or bulky brings great benefits for this period is considered the most critical in livestock.
\end{abstract}

Keywords: Forages; Deferral; Winter

\section{Introdução}

A criação de bovinos no Brasil corresponde em mais de $80 \%$ no sistema de pastejo direto, mostrando que este meio de criação, ainda é o mais barato para a espécie, seu custo da matéria seca fica em torno de 05 centavos o kg, sendo insuperável por qualquer outra tecnologia, porém no período seco do ano muitos produtores não fazem um planejamento correto, pois as gramíneas neste período diminuem sua produção e seu valor nutricional necessitando de um suporte para que os animais não venham a ser prejudicados pela qualidade e quantidade do alimento ofertado.

A produção de bovinos está diretamente relacionada com as plantas forrageiras, sendo elas responsáveis pelo fornecimento da maioria dos nutrientes necessários aos animais em pastejo, com um baixo custo. As 
CASTRO, W.J.R. et al. Suplementação de bovinos na seca. PUBVET, Londrina, V. 8, N. 5, Ed. 254, Art. 1685, Março, 2014.

gramíneas são mais predominantes que as leguminosas em países de clima tropical, se destacando na formação de pastagem em todo o território nacional.

Porém, é inquestionável que mesmo com esse potencial para produção de carne em regime de pasto, é comum a existência de inadequações nutricionais no que se refere à oferta de energia, proteína e mineral Siqueira (2001). Para evitar a perda de peso dos animais muitos pecuaristas fazem o uso da suplementação a pasto e substituem sal mineral pelos protéicos, energéticos ou rações de semiconfinamento. Estes suplementos disponibilizam além dos macro e microminerais, carboidratos não estruturais e proteína. Como resultado, o ambiente ruminal é enriquecido com nitrogênio e nutrientes digestíveis totais fermentescíveis. Os microrganismos se tornam mais eficientes ao degradar a fibra, os animais aumentam a ingestão de alimento e ganham mais peso. A suplementação na estação da seca é mais comum do que no período das águas e, ainda assim, muitas propriedades ainda não adotaram este tipo de manejo fazendo com que o sistema diminua seus índices de produtividades.

Várias pesquisas têm sido realizadas com o objetivo de reduzir a significativa perda de peso que ocorre durante o período de estacionalidade do ano, seja fornecendo fontes de nitrogênio não protéico como a uréia, ou suplementando com alimentos protéicos e energéticos. Uma das formas de se complementar o eventual déficit de proteína e energia que as pastagens apresentam durante o ano é por intermédio da suplementação. Porém para que se possa obter maiores sucesso com a suplementação, uma estratégia de vedação de pastagens tem que ser seguida, principalmente para os suplementos que contem uréia, pois com o uso deste, é necessário obter nas pastagens matéria seca suficiente para todos os animais. A vedação consiste em deixar o pasto em descanso por um período de tempo para que o mesmo possa ser estabelecer em quantidade e qualidade, visando o fornecimento no período de escassez de alimento, o correto é que esta tecnologia seja feita no final do período das águas entre março e abril, dependendo da região. Sendo 
CASTRO, W.J.R. et al. Suplementação de bovinos na seca. PUBVET, Londrina, V. 8, N. 5, Ed. 254, Art. 1685, Março, 2014.

assim o uso desta técnica associada à suplementação, ao uso de capineiras, fenação e silagem no período de estacionalidade do ano, trará resultados satisfatórios para a produção de bovinos criados exclusivamente a pasto, elevando assim seus índices zootécnicos e principalmente melhorando o bem estar animal.

\section{Diferimento de Pastagens}

O diferimento da pastagem consiste em deixar a pastagem em repouso no fim da estação das chuvas, possibilitando que a forragem acumulada seja utilizada durante o período de estiagem do ano. Essa estratégia de manejo é realizada para reduzir os efeitos desfavoráveis da estacionalidade produtiva das forrageiras tropicais sobre o desempenho animal durante o inverno Santos et al. (2010). Em climas tropicais, o ciclo de produção anual de forragem é determinado pelas fases das águas, da seca e os períodos de transição entre elas. Costa (2007) citou que o padrão cíclico no desenvolvimento dos ruminantes é determinado, quase exclusivamente, pelo clima que tem grande efeito no ciclo vegetativo das forrageiras tropicais, sendo a época chuvosa a que representa os períodos de desenvolvimento satisfatório.

No período de estiagem, que na maioria das regiões vai de junho a setembro as pastagens tem seu crescimento reduzido por condições climáticas, seu crescimento se limita em torno de $20 \%$ enquanto que no período das águas chega a $80 \%$. Porto et al.(2008), observou que as gramíneas do gênero Brachiaria acumulam de 77 a $90 \%$ da produção total de matéria seca durante o período das águas. Com esta grande diferença de crescimento dificulta o planejamento alimentar do rebanho ao longo do ano, pois as altas taxas de lotação permitidas no período das águas são bastante reduzidas durante o período seco Euclides, (1990). A baixa produção animal na época seca é atribuída, principalmente, ao baixo consumo de matéria seca (CMS), ou seja, ao baixo consumo de energia, e à deficiência de proteína e minerais nos pastos; nesta época, as pastagens apresentam frequentemente baixa 
CASTRO, W.J.R. et al. Suplementação de bovinos na seca. PUBVET, Londrina, V. 8, N. 5, Ed. 254, Art. 1685, Março, 2014.

disponibilidade e proporção de folhas verdes e alta de caule e material morto, e são pouco consumidas, mesmo que o suprimento de forragem total seja abundante Euclides et al., (1990).

Paulino \& Ruas 1988 mencionaram que o aumento da eficiência na produção de bovinos no Brasil está incondicionalmente relacionado à melhoria das condições de alimentação, sendo a suplementação uma das alternativas mais práticas para adequar suprimento de nutrientes aos requerimentos dos animais, especialmente durante a seca.

Sendo assim, um dos pontos a ser questionado numa propriedade é o planejamento alimentar do rebanho para a estação seca ou inverno. $O$ ajuste da oferta de forragem nessa época do ano pode ser feito de duas formas: reduzindo a taxa de lotação (venda de animais) ou armazenando alimento seja ele por pastagens diferidas ou através de silagem ou feno.

Uma vantagem do pastejo diferido está no seu condicionamento ao suplemento alimentar, ou seja, de acordo com as características qualitativas do volumoso, principalmente proporção de folhas e conteúdo de parede celular, quantidade de biomassa presente, espécie forrageira e palatabilidade, utilizam-se suplementos mais adequados à alimentação Balsalobre et al., (2003). Segundo Santos et al. (2009), o diferimento de pastagens pode ser entendido como uma estratégia de manejo que consiste em selecionar determinadas áreas da propriedade e excluí-las do pastejo, garantindo acúmulo de forragem para ser pastejada durante o período de escassez, minimizando os efeitos da sazonalidade de produção de forragem.

O sucesso desta técnica, esta relacionada à época do diferimento, uma vedação muito precoce fará com que o dossel forrageiro cresça de forma que sua estrutura se torne mais lignificada prejudicando assim seu consumo pelos animais, por outro lado uma vedação tardia correrá o risco do dossel não se estabelecer de forma ideal para ser administrado no período. Segundo Santos et al. (2009) para otimizar a suplementação em pastagens diferidas, a disponibilidade de forragem não deve ser limitante ao consumo animal. Nesse sentido, o período em que o pasto permanece diferido é fundamental para 
CASTRO, W.J.R. et al. Suplementação de bovinos na seca. PUBVET, Londrina, V. 8, N. 5, Ed. 254, Art. 1685, Março, 2014.

garantir produção de forragem em quantidade e qualidade. Pastagens diferidas por longo período possuem alta produção de forragem, porém de pior valor nutritivo.

Por outro lado, menor período de diferimento pode determinar baixa produção de forragem. Com isso, podem-se definir, para cada região e forrageira, períodos de diferimento mais adequados, em que a estrutura do pasto diferido proporciona bom desempenho animal (Santos et al., 2009). As gramíneas mais recomendadas para o diferimento de pastagens são as do gênero braquiária como as cultivares piatã, xaráes e marandú com exceção da Braquiária decumbens que não é resistente à cigarrinha das pastagens e já caiu em desuso, a não ser que a pastagem já esteja estabelecida, não há problemas de fazer o diferimento, os Cynodons também e bastante utilizado devido ao seu ótimo valor nutricional superando o gênero das braquiarias, as gramíneas do gênero panicum não são indicadas para essa técnica devida suas características de crescimento que é cespitosa (ereto), fazendo com que o controle da estrutura do dossel forrageiro seja mais difícil, outra desvantagem é a relação folha/colmo que é menor em relação às citadas.

De acordo com Valdinei (2004) com relação à qualidade, as forrageiras podem ser classificadas em três grupos distintos: o de alta qualidade, composto por gramíneas dos gêneros Panicum (tanzânia, mombaça, tobiatã, vencedor), Cynodon (estrela, coast cross e tiftons) e Pennisetum (cameroon, napier e anão), o de média qualidade formado pelas gramíneas do gênero Brachiaria (ruziziensis, decumbens e marandu), Hyparrhenia rufa (jaraguá) e Andropogon (planaltina e baeti), e o de baixa qualidade constituído pelas gramíneas do gênero Brachiaria (humidicola e dictyneura cv. Llanero). Segundo Euclides et al. (2007), as gramíneas mais indicadas são aquelas que apresentam baixo acúmulo de colmos e boa retenção de folhas verdes, o que resulta em menores reduções no valor nutritivo ao longo do tempo, destacando-se a maioria das gramíneas do gênero Braquiária. 
CASTRO, W.J.R. et al. Suplementação de bovinos na seca. PUBVET, Londrina, V. 8, N. 5, Ed. 254, Art. 1685, Março, 2014.

\section{Suplementação}

O período seco do ano, sem dúvida é o que mais traz prejuízos para a pecuária brasileira seja pela seca prolongada inesperada, ou pela falta de estratégia de muitos produtores, esta fase é conhecida pela perda qualitativa e quantitativa das pastagens, pois fatores climáticos como falta de chuva, fotoperíodo, temperatura e outros, afetam seu crescimento. Segundo Minson (1990), o valor nutritivo das gramíneas tropicais é baixo no período da seca, pois a maioria não atinge o valor mínimo de $7,0 \%$ de proteína bruta, o que limita o desenvolvimento dos microrganismos do rúmen, a digestibilidade e o consumo da forragem, resultando em baixo desempenho dos animais. Esta deficiência sazonal pode ser suprida pelo fornecimento de proteína adicional à dieta dos animais, tanto de origem vegetal, como também proveniente de compostos nitrogenados não-protéicos.

Sem uma suplementação adequada as pastagens por si só não atende as exigência mínimas de mantença para os bovinos que requerem $7 \%$ de proteína bruta na dieta Morais et al. (2010). Apesar de garantir um estoque de forragem para ser utilizado sob pastejo durante os meses de entressafra, o diferimento do uso da pastagem resulta em produção de forragem de limitado valor nutritivo (Santos et al., 2004). A qualidade da forragem, refletida no desempenho animal, é a resposta da interação entre inúmeros fatores abióticos e bióticos do ecossistema. Desta forma, o entendimento destas complexas inter-relações permite a adoção de práticas de manejo que propiciam a exploração do potencial genético dos animais, bem como da forragem disponível, Costa (2003). Sendo assim, se nesta fase não houver uma suplementação adequada na dieta dos animais, a fim de suprir os nutrientes deficientes na forragem, haverá redução no seu desempenho, pois nutrientes corporais são mobilizados para mantença, resultando assim, em aumento da idade de abate e redução da taxa de desfrute da fazenda e aumento do custo fixo do sistema Euclides et al.(1998). 
CASTRO, W.J.R. et al. Suplementação de bovinos na seca. PUBVET, Londrina, V. 8, N. 5, Ed. 254, Art. 1685, Março, 2014.

Com isso a suplementação de animais em pastejo durante o período da seca tem por finalidade suprir esta deficiência nutricional das pastagens permitindo assim eliminar as fases negativas do crescimento, o que melhora a digestibilidade das forrageiras, minimiza os efeitos de enchimento ruminal, possibilita maior consumo de forragem e, consequentemente, melhora o desempenho animal Euclides et al. (1998). O tipo de suplemento empregado, seu nível de fornecimento e composição, bem como os ganhos proporcionados devem ser considerados no momento da sua implementação em sistemas de produção com base no uso de forrageiras, para a maior eficiência do sistema e a maximização da renda do produtor rural Carvalho et al.(2009).

Todavia, quando se almeja maior desempenho animal, pode-se adotar a estratégia de suplementação do pasto diferido para complementar o valor nutritivo da forragem disponível e/ou melhorar a conversão alimentar Euclides et al. (2007). De todos os nutrientes, o nitrogênio é o mais limitante, e consequentemente, 0 de maior prioridade para suplementação. Sua participação na dieta do animal é fundamental para manter o crescimento normal das bactérias ruminais, pois as bactérias do rúmen afetam diretamente a digestibilidade e o consumo, Sales et al.(2009).

Para Reis et al. (2006), a suplementação dos animais em pastejo pode ser realizada com vários objetivos; como corrigir a deficiência de nutrientes da forragem; aumentar a capacidade de suporte das pastagens; fornecer aditivos; fornecer medicamentos e auxiliar no manejo das pastagens. Segundo Paulino et al. (2001) com o uso de suplementos protéicos, haverá melhora no consumo e na digestibilidade do pasto seco, com isso associado a taxas de lotação adequadas, torna possível a exploração de vasta quantidade de forragem fibrosa de baixa aceitação, as quais normalmente são desperdiçadas durante ou ao final de cada estação seca. Para que o suplemento seja usado, é necessário o conhecimento dos seguintes itens: I) conhecer as exigências dos animais; II) estimar o que está disponível como forragem; III) fornecer somente os nutrientes necessários para preencher a diferença entre o 
CASTRO, W.J.R. et al. Suplementação de bovinos na seca. PUBVET, Londrina, V. 8, N. 5, Ed. 254, Art. 1685, Março, 2014.

disponível pela forragem e a exigência nutricional dos animais Malafaia et al. (2003).

Um dos principais ingredientes utilizados no período da seca é o nitrogênio não protéico (uréia), onde o mesmo faz parte dos minerais proteinados, sua substituição pela proteína verdadeira pode chegar até $25 \%$ de acordo com as pesquisas, a principal característica dessa fonte de nutriente é o seu preço, pois está muito abaixo das fontes de proteína verdadeira como farelo de soja, torta de girassol e outros. A substituição da proteína verdadeira pelo nitrogênio não-protéico (NNP) da uréia em dietas para ruminantes é possível somente em virtude da capacidade dos microrganismos ruminais de converter o NNP em proteína de alto valor biológico Paixão Lopes et al. (2006). A uréia é incluída na alimentação de ruminantes, com o objetivo de substituir a proteína natural, de maior custo, ou acrescentar nitrogênio em sistemas de produção com forragens de baixo valor protéico. O principal objetivo da uréia na suplementação é manter a concentração de amônia ruminal em níveis elevados, aumentando, assim, o consumo por intermédio de melhorias na fermentação ruminal Kabeya (2002).

A adoção da técnica de suplementação alimentar em um sistema de produção animal a pasto deverá, antes de mais nada, tornar a exploração mais lucrativa. A lucratividade resultante do sucesso da aplicação desse tipo de manipulação nutricional normalmente se encontra associada a algumas vantagens produtivas Almeida e Azevedo (1996). Para uma alta produção animal em pastagens, três condições básicas devem ser atendidas, Santos (2004): (a) deve ser produzida uma grande quantidade de forragem de bom valor nutritivo, cuja distribuição estacional deve coincidir com a curva de exigências nutricionais dos animais; (b) uma grande proporção dessa forragem deve ser colhida pelos próprios animais (consumo), e (c) a eficiência de conversão dos animais deve ser elevada. A primeira condição é muito difícil de ser atendida, porque, na maioria das pastagens no mundo, o suprimento de forragem ao longo do ano não coincide exatamente com as necessidades dos rebanhos Santos (2004). 
CASTRO, W.J.R. et al. Suplementação de bovinos na seca. PUBVET, Londrina, V. 8, N. 5, Ed. 254, Art. 1685, Março, 2014.

A adoção de fontes de nitrogênio não protéico, como o sal com uréia, associada às misturas minerais, é a forma mais frequentemente utilizada para eliminar a deficiência protéica durante o período seco. Porém deve-se lembrar que essa suplementação é direcionada aos microrganismos ruminais, responsáveis pela digestão das forragens, e não aos animais diretamente. Além disso, essa tecnologia é recomendada fundamentalmente à manutenção dos animais, não havendo pretensão de ganhos de peso significativos.

Sem dúvida, as práticas que permitem maximizar o consumo do volumoso quer seja em pastejo, ou com o uso de forragem conservada, associada a condições ruminais adequadas levam a eficiente digestão da fração fibrosa, bem como a utilização dos compostos nitrogenados,resultando em adequada. Neste contexto, a suplementação seja pela utilização de alimentos concentrados ou com volumosos de boa qualidade se destaca como uma das formas de se complementar o eventual déficit de proteína e energia que as forragens apresentam durante o ano, tendo como principais vantagens à otimização da utilização das forragens, aumentando a taxa de lotação por meio do fornecimento de nutrientes aos animais, o que contribui para a redução na idade ao primeiro parto, intervalo entre partos e idade ao abate Lana, (2002). Em sistemas de produção baseados em forragens como a única fonte de nutrientes, o desempenho dos animais pode ser menor que o determinado geneticamente e, ou o desejado para satisfazer os objetivos da produção, uma vez que a eficiência máxima de utilização da dieta resulta do fornecimento de dietas balanceadas nutricionalmente e o desempenho animal é limitado a aquele suportado pelo primeiro nutriente limitante NRC, (2001). Segundo Thiago (1999), a maior produtividade dos sistemas de produção de carne a pasto só será alcançada se houver ajuste entre a curva sazonal de oferta de nutrientes das pastagens e a crescente demanda de nutrientes pelo animal.

Este fato é possível por meio do uso da suplementação alimentar, desde que esta apresente relação custo: benefício favorável. De acordo com Pedreira et al. (2001), a intensidade e frequência de pastejo, espécie animal, método 
CASTRO, W.J.R. et al. Suplementação de bovinos na seca. PUBVET, Londrina, V. 8, N. 5, Ed. 254, Art. 1685, Março, 2014.

de apreensão da forragem, pisoteio, deposição de fezes e urina e, eventualmente, de saliva podem causar alterações substanciais na persistência, produtividade e composição botânica do dossel. Sempre que as relações entre a estrutura da pastagem e o processo de pastejo dos animais são abordadas, registram-se a escassez dessas informações para as condições de pastagens tropicais.

\section{Utilização de capineiras, silagens e fenação}

Outra saída para suplementação no período de estiagem é o uso de capineiras esta técnica e muito utilizada principalmente entre os pequenos produtores, consiste em implantar na propriedade uma forrageira de alta produção para ser fornecida no período da seca, as mais utilizadas são capim elefante e a cana-de-açúcar, suas produções ultrapassam 30 tonelada de matéria seca por hectare. Ressalta-se, desde logo, que as capineiras, se bem utilizadas, constituem em um recurso valioso, produzindo forragem de boa qualidade, a baixo custo e alto rendimento para suplementar os animais no período critico do ano. Já a utilização da silagem requer um nível tecnológico maior na propriedade fazendo com que seu uso seja mais restrito entre os produtores.

A ensilagem consiste na preservação de forragens úmidas, recémcolhidas ou pré-secadas, com elevado valor nutritivo, para ser administrada na época de escassez de alimento. Apesar de ter sido introduzida de maneira relativamente lenta no país, a ensilagem teve alguma expansão a partir do final da década de 60 e início dos anos 70, graças aos esforços dos órgãos de extensão rural e do começo dos trabalhos experimentais sobre os processos fermentativos Faria (1995). O processo de ensilagem é extremamente complexo em razão de vários fatores que se relacionam, tais como espécies forrageiras utilizadas e suas características físico-químicas. Além disso, existem variações na miclofora das forrageiras, condições climáticas, 
CASTRO, W.J.R. et al. Suplementação de bovinos na seca. PUBVET, Londrina, V. 8, N. 5, Ed. 254, Art. 1685, Março, 2014.

operações de ensilagem, duração do período de conservação da silagem e manejo da alimentação após a abertura do silo.

A preservação dos alimentos, por meio da ensilagem deve-se à produção de ácidos orgânicos, principalmente o ácido lático, a partir de açúcares solúveis, o que promove redução do $\mathrm{pH}$ e, consequentemente, inibição de microrganismos deletérios indesejáveis. Este processo ocorre em condições de anaerobiose, de modo que se requer uma boa compactação e vedação dos silos Mcdonald, (1981). O milho, o sorgo e o capim-elefante são as principais forrageiras usadas para ensilagem, sendo o milho a mais comum e de maior valor nutritivo dentre elas. No entanto, outras plantas podem ser utilizadas para silagem, como: girassol, cana-de-açúcar e outras forrageiras como o Tanzânia, Brachiarias como o Brizantha, MG-5, capim Paraíso, Mombaça e Milheto. De acordo com Pereira et al. (2004), as silagens de gramíneas tropicais, como alternativa às culturas tradicionais, apresentam como vantagens: ser cultura perene, além da possibilidade do aproveitamento do excedente de produção das pastagens, na época das águas.

A grande produção por área é a principal característica dessas espécies, havendo, naturalmente, diferença entre os cultivares e a idade da planta. $\mathrm{Na}$ fenação, a forragem é desidratada de tal forma que permanece biologicamente inativa com respeito à atividade enzimática da planta e dos microrganismos. 0 baixo conteúdo de umidade dos fenos permite que este seja transportado e comercializado em função do reduzido peso em relação à unidade de matéria seca (MS). A fenação é a principal prática de conservação nas regiões onde ocorrem condições apropriadas para a secagem.

Contudo, ela pode também ser usada em locais de maior precipitação onde a ensilagem é considerada de difícil adoção devido às características da forragem, alta temperatura ou tradição. Para produzir um feno de alta qualidade pelo menos duas condições são necessárias: a forragem a ser cortada deve ser de boa qualidade e a secagem deve ser feita com um mínimo de perda de nutrientes, que se consegue com uma secagem rápida que leva a planta à sua inatividade. O processo de fenação envolve remoção de grande 
CASTRO, W.J.R. et al. Suplementação de bovinos na seca. PUBVET, Londrina, V. 8, N. 5, Ed. 254, Art. 1685, Março, 2014.

quantidade de água da planta. De um modo geral uma forrageira durante a fase de crescimento vegetativo, em condições normais de umidade no solo, apresenta 75 a $85 \%$ de água ( 15 a $25 \%$ de matéria seca), durante a fase de floração cerca de 65 a 75\% de água e na fase de sementes maduras, cerca de $55 \%$.

A época ideal de corte seria aquela em que a forrageira estaria mais adequada para a fenação, sob o aspecto qualitativo e quantitativo. Portanto esta época não pode ser definida em termos somente de crescimento ou de datas de cortes pré-fixadas, mas sim em períodos de descanso da cultura, condições locais do meio, aspectos econômicos, etc. Convém, portanto, enfatizar que a qualidade da forragem à época do corte é de importância primária na qualidade do feno. Sendo assim seja qual for a técnica utilizada para suplementação de bovinos no período seco do ano, tem que haver um planejamento antecipado para poder obter resultados satisfatórios no sistema como um todo, evitando assim surpresas desagradáveis.

\section{Considerações Finais}

A suplementação no período seco do ano representa uma forma de introduzir um novo tipo de manejo a propriedade de modo a otimizar o uso da forragem ao longo do ano disponibilizando nesses períodos críticos um aporte de nitrogênio ao sistema que servirá para estimular o consumo e consequentemente aumentar a produção. A utilização da técnica de suplementação alimentar em sistemas de produção animal em pasto devem, como em qualquer atividade econômica, respeitar uma relação entre custo e benefício que otimize o sistema. Para isso é fundamental o acompanhamento de todas as etapas do processo e que algumas condições sejam estabelecidas. 


\section{Referências}

ALMEIDA, A. J. e AZEVEDO, C. 1996. Semiconfinamento - como ganhar dinheiro com boi gordo quando os outros estão perdendo. Globo. São Paulo - SP. 184p.

BALSALOBRE, M.A.A. et al. Composição química e fracionamento do nitrogênio e dos car;boidratos do capim tanzânia irrigado sob três níveis de resíduo pós-pastejo. Rev. Bras. Zootec., Viçosa, v. 32, n. 3, p. 519-528, 2003.

CARVALHO, D.M.G.; ZERVOUDAKIS, J.T.; CABRAL, L.S.; PAULA, N.F.; MORAES, E.H.B.K.; OLIVEIRA, A.A.; KOSCHECK, J.F.W. Fontes de energia em suplementos múltiplos para recria de bovinos em pastejo no período da seca: desempenho e análise econômica. Revista Brasileira de Saúde e Produção Animal, v.10, p.760 $\square 73,2009$.

COSTA, D.I., SCHEFFER-BASSO, S.M, FAVERO, D., FONTANELI, R.S. Caracterização morfofisiológica e agronômica de Paspalum dilatatum Poir. biótipo Virasoro e Festuca arundinacea Schreb. 2. Disponibilidade de forragem e valor nutritivo. Revista Brasileira de Zootecnia. V. 32 n.5, p. 1061-1067, 2003.

COSTA, K.A.P.; OLIVEIRA, I.P.; FAQUIN, V. Intervalo de corte na produção de massa seca e composição químico-bromatológica da Brachiaria brizantha CV MG-5. Ciência Agrotécnica Lavras, v.31, n.4, p.1197-1202, 2007.

EUCLIDES, V.P.B.; FLORES, R.; MEDEIROS, R.N.; OLIVEIRA, M.P. Diferimento de pastosde braquiária cultivares Basilisk e Marandu, na região do Cerrado. Pesquisa Agropecuária Brasileira, v.42, n.2, p.273-280, fev. 2007.

EUCLIDES, V.P.B.; EUCLIDES FILHO, K.; ARRUDA, Z.J. et al. Desempenho de novilhos em pastagens de Brachiaria decumbens submetidos a diferentes regimes alimentares. Revista Brasileira de Zootecnia, v.27, n.2, p.246-254, 1998.

EUCLIDES, V.P.B.; VALLE, C.B.; SILVA, J.M. et al. Avaliação de forrageiras tropicais manejadas para produção de feno em pé. Pesquisa Agropecuária Brasileira, v.25, n.3, p.393-407, 1990.

KABEYA, S. K. et al. Suplementação de Novilhos Mestiços em Pastejo na Época de Transição Água-Seca: Desempenho Produtivo, Características Físicas de Carcaça, Consumo e Parâmetros Ruminais. Revista Brasileira de Zootecnia, v.31, n.1, p.213-222, 2002.

LANA, R.P. et al. Sistema de suplementação alimentar para bovinos de corte em pastejo. Simulação. Revista Brasileira de Zootecnia, v.31, n.1, p.223-231, 2002.

MALAFAIA, P. et al. Suplementação protéico-energética para bovinos criados em pastagens, Revista Brasileira de Zootecnia, v. 15, n. 12, p. 101-109, 2003.

MINSON, D.J. Forage in ruminant nutrition. New York: Academic Press, 1990. 483p.

MCDONALD, P. The biochemistry of silage. John Wiley \& Sons. Chichester. p. 218, 1981.

MORAES, E.H.B.K.; PAULINO, M.F.; MORAES, K.A.K. et al. Exigências de proteína de bovinos anelorados em pastejo. Revista Brasileira de Zootecnia, v.39, n.3, p.601-607, 2010.

NRC - NATIONAL RESEARCH COUNCIL. Nutrient requeriments of beef cattle.

242p. 2001. 
REIS, R.A.; RODRIGUES, L.R.A.; PEREIRA, J.R.A. Suplementação como estratégia para o manejo das pastagens. In: SIMPÓSIO SOBRE MANEJO DAS PASTAGENS, 13., 1997, Piracicaba. Anais... Piracicaba: FEALQ, 1997. p. 123-150.

THIAGO, L. R. L. 1999. Suplementação de Bovinos em Pastejo - Aspectos práticos para o seu uso na mantença ou ganho de peso. Palestra apresentada no $11^{\circ}$ Encontro de Tecnologias para a Pecuária de Corte. Campo Grande - MS.

PAULINO, M.F.; RUAS, J.R.M. Suplementação na recria de bovinos de corte. Rev. Bras. Zootec, v.13, n.153/154, p, 68-80, 2001.

PAULINO, M.F. e RUAS, J.R.M. Considerações sobre recria de bovinos de corte. Informativo Agropecuário, V.13, n. 153/154, p.68-79, 1988.

PAIXÃO, L.P. e FILHO, V.C.S, LEÃO, I.M. Uréia em dietas para bovinos: consumo, digestibilidade dos nutrientes, ganho de peso, características de carcaça e pbrodução microbiana. Rev. Bras. Zootec., v.35, n.6, p.2451-2460, 2006.

PEDREIRA, C.G.S.; MELLO, A.C.L.; OTANI, L. O processo de produção de forragem em pastagens. In: A PRODUÇÃO ANIMAL NA VISÃO DOS BRASILEIROS, 2001, Piracicaba. Palestras... Piracicaba: Fundação de Estudos Agrários Luiz de Queiroz, 2001. p.927.

PEREIRA, O. G. et al. II SIMPÓSIO SOBRE O MANEJO ESTRATÉGICO DA PASTAGEM. Viçosa: UFV, 2004. 545 p.

PORTO, M.O.; PAULINO, M.F.; VALADARES FILHO, S.C. et al. Formas de utilização do milho em suplementos para novilhos na fase de terminação em pastagem no período das águas: desempenho e parâmetros nutricionais. Revista Brasileira de Zootecnia, v.37, n.12, p.2251-2260, 2008.

REIS, R. A., TEIXEIRA, I. A. M. de A., SIQUEIRA, G. R. Impacto da qualidade da forragem na produção animal. Revista Brasileira de Zootecnia, v.35, p.580-608, 2006.

SALES, M.F.L.; PAULINO, M.F.P.; VALADARES FILHO, S.C. et al. Composição corporal e requisitos energéticos de bovinos de corte sob suplementação em pastejo. Revista Brasileira de Zootecnia, v.38, n.7, p.1355-1362, 2009.

Santos, E.D.G; Paulino, M.F.; Filho, S.C.V. et al. Consumo, digestibilidade e parâmetros ruminais em tourinhos Limousin-Nelore, suplementados durante a seca em pastagem diferida de Brachiaria decumbens. Rev. Bras. Zootec. vol.33 no.3 Viçosa May/June 2004.

SANTOS, M. E. R.; FONSECA, D. M.; BALBino, E. M. et al. Caracterização de Perfilhos em Pastos de Capim-braquiária Diferidos e Adubados com Nitrogênio. Revista Brasileira de Zootecnia, v. 38, 2009. 
SANTOS, E.D.G; PAULINO, M.F.; FILHO, S.C.V. et al. Terminação de tourinhos Limousin X Nelore em pastagem diferida de Brachiaria Decumbens stapf, durante a estação seca, alimentados com diferentes concentrados. Rev. Bras. Zootec. v.33 n.6, 2004.

SANTOS, M. E. R.; FONSECA, D. M.; BALBINO, E. M. et al. SANTOS, M. E. R.; FONSECA, D. M.; BALBINO, E. M. et al. Correlações entre número de perfilhos, índice de tombamento, massa dos componentes morfológicos e valor nutritivo da forragem em pastos diferidos de capimbraquiária. Revista Brasileira de Zootecnia, v.39 n.3, 2010.

SIQUEIRA, G. B. Efeito da suplementação sobre o desempenho, ingestão voluntária e eficiência alimentar de bovinos de corte consumindo volumoso de baixa qualidade. 2001. 50p. Dissertação (Mestrado em Zootecnia) - Universidade Estadual Paulista, Ilha Solteira. 